\title{
Spectral analysis of the angular distribution function of back reflectors for thin film silicon solar cells
}

J. Escarré, F. Villar, J.M. Asensi, J. Bertomeu, J. Andreu

CeRMAE - Departament de Física Aplicada i Òptica, Universitat de Barcelona, Av. Diagonal 647, 08028 Barcelona, Spain

\begin{abstract}
Nowadays, one of the most important challenges to enhance the efficiency of thin film silicon solar cells is to increase the short circuit intensity by means of optical confinement methods, such as textured back-reflector structures. In this work, two possible textured structures to be used as back reflectors for n-i-p solar cells have been optically analysed and compared to a smooth one by using a system which is able to measure the angular distribution function (ADF) of the scattered light in a wide spectral range $(350-1000 \mathrm{~nm})$. The accurate analysis of the ADF data corresponding to the reflector structures and to the $\mu \mathrm{c}-\mathrm{Si}: \mathrm{H}$ films deposited onto them allows the optical losses due to the reflector absorption and its effectiveness in increasing light absorption in the $\mu \mathrm{c}-\mathrm{Si}: \mathrm{H}$ layer, mainly at long wavelengths, to be quantified.
\end{abstract}

\section{Introduction}

In $\mu \mathrm{c}-\mathrm{Si}: \mathrm{H}$ solar cells, optical confinement strategies are necessary to enhance the light absorption in the active layer of the cell. These strategies are preferable to increasing the thickness of the intrinsic layer as they avoid a reduction of the internal electric field and, consequently, the loss of collection efficiency. The generation of a random texture [1-2] or a periodic structure [3-4] in order to disperse the incoming light and increase its optical path inside the cell is the most usual approach. This can be done by texturing the TCO layers [5-6] or the substrate itself [7]. This is usually accompanied by the use of a back reflector layer both in substrate [8] and superstrate [9] structures.

The study of the angular distribution function (ADF) of the light scattered by a textured surface is a powerful tool, enabling its influence on the optical behaviour of the solar cell to be studied 
without building the whole device. This measurement is usually carried out at one or two fixed wavelengths [10]. Other studies show a dependency between the angular distribution of the scattered light and the relation between the RMS roughness and the wavelength [1]. The aim is to find a surface morphology which disperses the maximum amount of light with wavelengths between 600 and $1000 \mathrm{~nm}$.

In this work an experimental set up developed to determine the ADF of the light scattered by a rough surface in a wide spectral range (between 350 and $1050 \mathrm{~nm}$ ) is presented. By using it, two kinds of textured back reflector structures were analysed before and after the deposition of a $\mu \mathrm{c}-\mathrm{Si}: \mathrm{H}$ layer. The results obtained with these reflectors are compared with those of a smooth one.

\section{Experimental}

The spectral ADF measurements were carried out in a system that allows us to measure the light scattered by a rough surface. A mercury lamp was used as light source and the different wavelengths were selected by means of a double-grating monochromator. The light was guided into the system by an optical fibre and was then focused, crossing through the sample, on the detector in its initial point. The sample can rotate around its own axis to change the incident angle, and the detector rotates around the sample at a fixed distance. To correct eventual changes caused by instabilities of the lamp, a beam splitter and a fixed detector were used. Both detectors were silicon photodiodes with an active area of $16 \mathrm{~mm}^{2}$. The light was chopped and the signals of both detectors were measured by two lock-in amplifiers. For an incident beam perpendicular to the sample, the ADF is determined by:

$$
A D F(\alpha)=\frac{S(\alpha)}{S_{\text {Total }} \cdot \Delta \Omega}
$$

where $S(\alpha)$ is the signal obtained at an angle $\alpha, S_{\text {Total }}$ is the signal of the incident beam and $\Delta \Omega$ is the solid angle of the detector. Angle $\alpha=180^{\circ}$ corresponds to specular reflection and $\alpha=0^{\circ}$ would correspond to the non-scattered transmitted beam. 
In the case of reflectors with random textures, revolution symmetry around the axis determined by the incident beam was assumed. This symmetry allowed us to determine all the scattered light by integrating the ADF from $\alpha=90^{\circ}$ to values close to $180^{\circ}$. The specular reflection was then measured by slightly rotating the sample. From these measurements, the reflection haze parameter was calculated as the ratio of scattered light to total reflected light (scattered + specular). The absorption in the samples was estimated from $1-\mathrm{R}$, where $\mathrm{R}$ is the total reflectance (scattered + specular).

In order to verify the accuracy of the system a Spectralon ${ }^{\circledR}$ lambertian diffuser was measured and the result obtained (figure 1) showed a good agreement with the expected one for all the wavelengths used. The measurements carried out with this illumination system at a fixed wavelength of $633 \mathrm{~nm}$ matched with those obtained by using a red-diode laser.

Three different back reflectors were studied. Back reflectors A and B consisted of a silver layer $(50 \mathrm{~nm})$ deposited respectively on a smooth substrate (Corning glass) and on a randomly textured substrate (commercially available Asahi-U substrate). Back reflector C was kindly offered by IPV Forschungzentrum Jülich, and consisted of a glass/Ag/ZnO:Al structure, where the $\mathrm{ZnO}$ :Al layer has been etched using $\mathrm{HCl}$ to obtain a nanometric roughness. An intrinsic $\mu \mathrm{c}-\mathrm{Si}: \mathrm{H}$ layer, with a thickness around $800 \mathrm{~nm}$, was deposited by HWCVD on top of the three back reflectors. These samples were also optically analysed to observe the influence of these back reflector structures on the absorption of the silicon layer.

\section{Results and Discussion}

The ADF of the scattered light for the back reflector structures B and C, and their AFM images are presented in figure 2. Both back reflectors exhibit a random texture with a RMS roughness of $28 \mathrm{~nm}$ for reflector B and $31 \mathrm{~nm}$ for reflector C. The measured RMS roughness for planar reflector (A) was $1 \mathrm{~nm}$, and no scattered light was detected. For reflector B, the ADF did not present interferences and its shape was simply a consequence of the reflector morphology (figure 2a). 
For the structure $\mathrm{C}$, the $\mathrm{ADF}$ showed interferences due to the layer of $\mathrm{ZnO}$ : $\mathrm{Al}$ (figure $2 \mathrm{~b}$ ). The maxima in the scattered light were around 470,570 and $750 \mathrm{~nm}$ and these corresponded to minima in the specular light. This fact indicates that, in spite of the light dispersion produced by the roughness, many of the photons were not scattered and their coherence was maintained giving interferences in the $\mathrm{ZnO}: \mathrm{Al}$ layer. It is also important to point out that when the relation between the ADF and the morphology of a reflector has to be studied, a metallic layer should be the first surface in order to avoid interference effects, especially in the cases where the ADF measurement is done by using only a few wavelengths. The ADF of the back reflector $\mathrm{C}$ shows that the thickness of the $\mathrm{ZnO}$ :Al layer should play an important role to obtain a maximum in the scattered light around $800-900 \mathrm{~nm}$, which is the zone where a higher improvement of the optical behaviour of a solar cell can be obtained.

Total diffuse light was calculated from the previous ADF, by assuming revolution symmetry. The haze reflection parameter obtained was very similar for both rough structures and its dependency with the wavelength is shown in figure 3 . This fact certifies the narrow relation that exists between the morphology of a surface and the amount of light that it is able to scatter. Also a reduction of haze when increasing wavelength was observed for these reflectors, due to a loss in the scatter efficiency for their nanometric texture when the wavelength is increased. This fact shows the importance of considering the ratio between the RMS roughness and the wavelength in order to enhance the scattered light in the required spectral range.

After deposition of a $\mu \mathrm{c}-\mathrm{Si}: \mathrm{H}$ layer on these reflectors, the RMS roughness values were $8 \mathrm{~nm}$, $26 \mathrm{~nm}$ and $34 \mathrm{~nm}$ for the reflectors A, B and C respectively. Only the sample on the smooth reflector showed a significant increase in its roughness. This increase is due to the silicon microstructure which is smaller than the approximately $30 \mathrm{~nm}$ obtained for reflectors B and C. For this reason, no significant changes have been obtained in the morphology for reflectors B and $\mathrm{C}$ with the silicon layer on top.

The ADF corresponding to these samples presented interferences which were related to the $\mu \mathrm{c}-\mathrm{Si}: \mathrm{H}$ layer. From these measurements, an estimation of the light absorbed in the silicon film 
on the three back reflectors can be made (figure 4). In addition to $1-\mathrm{R}$ curves corresponding to the reflector/Si structures, those corresponding to the back reflectors are also presented.

The absorption of the rough reflector $\mathrm{B}$ was higher than the one obtained for reflector $\mathrm{A}$, specially, for the wavelengths between 450 and $600 \mathrm{~nm}$. This fact has also been reported in other studies [11] and a similar increase in the absorption of rough silver layers respect to smooth ones has been measured by means of Photothermal Deflection Spectroscopy (PDS) [12]. For reflector $\mathrm{C}$, the highest absorption was obtained in the short wavelength region of the spectra, decreasing to 0.3 around $850 \mathrm{~nm}$. This high absorption is due to the optical confinement which takes place inside the $\mathrm{ZnO}$ :Al layer. Thus, when a photon is scattered with an angle higher than the limit one ( $\mathrm{ZnO}: \mathrm{Al} /$ air interface) it remains caught inside the TCO layer until it is absorbed. For this reason, the measured $1-\mathrm{R}$ decreased as a function of the scattered light and the higher absorption was obtained for shorter wavelengths, where scattering is higher. However, this optical confinement inside the TCO layer would not take place in the whole device because the refraction index of the silicon is higher than the $\mathrm{ZnO}: \mathrm{Al}$ one. Also, although the absorption of the back reflector would remain high in the spectral range from $350 \mathrm{~nm}$ to 600 $\mathrm{nm}$, it will not be important because the majority of photons with these wavelengths should be totally absorbed in the active layer of the solar cell.

For the three back reflectors with the silicon layer on top, similar absorption values were obtained at short wavelengths. At longer wavelengths, absorption in the silicon samples deposited onto rough reflectors (B and C) was very similar and considerably higher than that of the sample on the smooth back reflector. For instance, the mean values of $1-\mathrm{R}$ for a-Si:H samples on structures A and B in the region between 900 and $1000 \mathrm{~nm}$ were around 0.1 and 0.7 , respectively. This important increase in the absorption has to take place in the silicon layer because the measured absorption for both back reflectors was around 0.01 in that wavelength range. This fact along with the high absorption obtained for the reflector $\mathrm{C}$, with or without silicon, indicates that the used nanometric texture is really optimal for optical confinement. In spite of these high values of $1-\mathrm{R}$ in the near infrared region, which agree with those obtained for solar cells with similar thicknesses [13], the quantum efficiency of the solar cells obtained 
using this kind of technology is not greater than 0.1 for the wavelengths near to $1000 \mathrm{~nm}$ [14]. These important losses can be explained by means of the important absorption which takes place in the TCO and doped layers.

\section{Conclusions}

In this work a system able to measure the ADF of the scattered light quantitatively in a wide spectral range has been presented. This setup has been used to study the optical behaviour of three different back reflectors and their influence on the absorption of a thin $\mu \mathrm{c}-\mathrm{Si}: \mathrm{H}$ layer. For the reflector that consisted in a rough silver layer, a higher absorption than for the smooth one has been obtained. The highest absorption has been measured for the reflector with a TCO layer on top. After the deposition of the $\mu \mathrm{c}-\mathrm{Si}: \mathrm{H}$ layer a higher absorption in the near infrared region is observed for both samples on rough reflectors. This indicates that the nanometric texture tested is really optimal for the optical confinement. Nevertheless, the low values usually attained for the quantum efficiency in that region compared to the absorption in the films point out that the TCO and doped layers are also key issues for the optical optimisation of the devices.

\section{Acknowledgements}

The authors thank Dr. Bern Rech from IPV Forschungzentrum Jülich for kindly supplying the glass/Ag/ZnO:Al back reflector. This work was supported by the Spanish Government (ENE2004-07376-C03-01/ALT). 


\section{References}

[1] O. Kluth, C. Zahren, H. Stiebig, B. Rech and H. Schade, Proceedings of $19^{\text {th }}$ European Photovoltaic Solar Energy Conference and Exhibition, Paris, 2004, Vol. II, p. 1587.

[2] J. Escarré, F. Villar, M. Fonrodona, D. Soler, J.M. Asensi, J. Bertomeu, J. Andreu, Proceedings of $19^{\text {th }}$ European Photovoltaic Solar Energy Conference and Exhibition, Paris, 2004, Vol. II, p.1359.

[3] C. Eisele, C.E. Nebel, M. Stutzmann, J. Appl. Phys. 89 (2001) 7722.

[4] N. Senoussaoui, M. Krause, J. Müller, E. Bunte, T. Brammer, H. Stiebig, Thin Solid Films 451-452 (2004) 397-401.

[5] O. Kluth, B. Rech, L. Houben, S. Wieder, G. Schöpe, C. Beneking, H. Wagner, A. Löffl, H.W. Schock, Thin Solid Films 351 (1999) 247-253.

[6] J. Müller, G. Schöpe, O. Kluth, B. Rech, M. Ruske, J. Trube, B. Szyszka, X. Jiang, G. Bräuer, Thin Solid Films 392 (2001) 327-333.

[7] N. Chuansuwanich, P.I. Widenborg, P. Campbell, A.G. Aberle, Tech. Digest $14^{\text {th }}$ International Photovoltaic Science and Engineering Conference, Bangkok, 2004, p. 325.

[8] T. Brammer, W. Reetz, N. Senoussaoui, O. Vetterl, O. Kluth, B. Rech, H. Stiebig, H. Wagner, Sol. Energy Mater. Sol. Cells 74 (2002) 469-478.

[9] J. Müller, B. Rech, J. Springer, M. Vanecek, Solar Energy 77 (2004) 917-930

[10] J. Krc, M. Zeman, O. Kluth, F. Smole, M. Topic, Thin Solid Films 426 (2003) 296-304.

[11] D. Beaglehole, O. Hunderi, Phys. Rev. B 2 (1970) 309-321.

[12] J. Springer, A. Poruba, L. Müllerova, M.Vanecek, O. Kluth, B. Rech, J. Appl. Phys. 95 (2004) 1427-1429.

[13] J. Springer, B. Rech, W. Reetz, J. Müller, M. Vanecek, Sol. Energy Mater. Sol. Cells 85 (2005) 1-11.

[14] K. Yamamoto, M. Yoshimi, Y. Tawada, Y. Okamoto, A. Nakajima, Sol. Energy Mater. Sol. Cells 66 (2001) 117-125. 


\section{Figure captions}

Figure 1. Measured angular distribution function (ADF) of the Spectralon® lambertian diffuser from 400 to $1000 \mathrm{~nm}$ (a) and the comparison of its ADF with the expected one for an ideal lambertian diffuser at a wavelength of $600 \mathrm{~nm}(\mathrm{~b})$.

Figure 2. ADF and AFM images for reflector structure B (a) and for reflector structure C (b).

Figure 3. Measured spectral dependencies of the haze parameters for reflector structures B and C.

Figure 4. Absorption values for the three studied reflectors (open symbols) and for the corresponding reflector/ $\mu \mathrm{c}-\mathrm{Si}: \mathrm{H}$ structures (full symbols). The results for the structures $\mathrm{A}, \mathrm{B}$ and $\mathrm{C}$ are represented in (a), (b) and (c) respectively. 


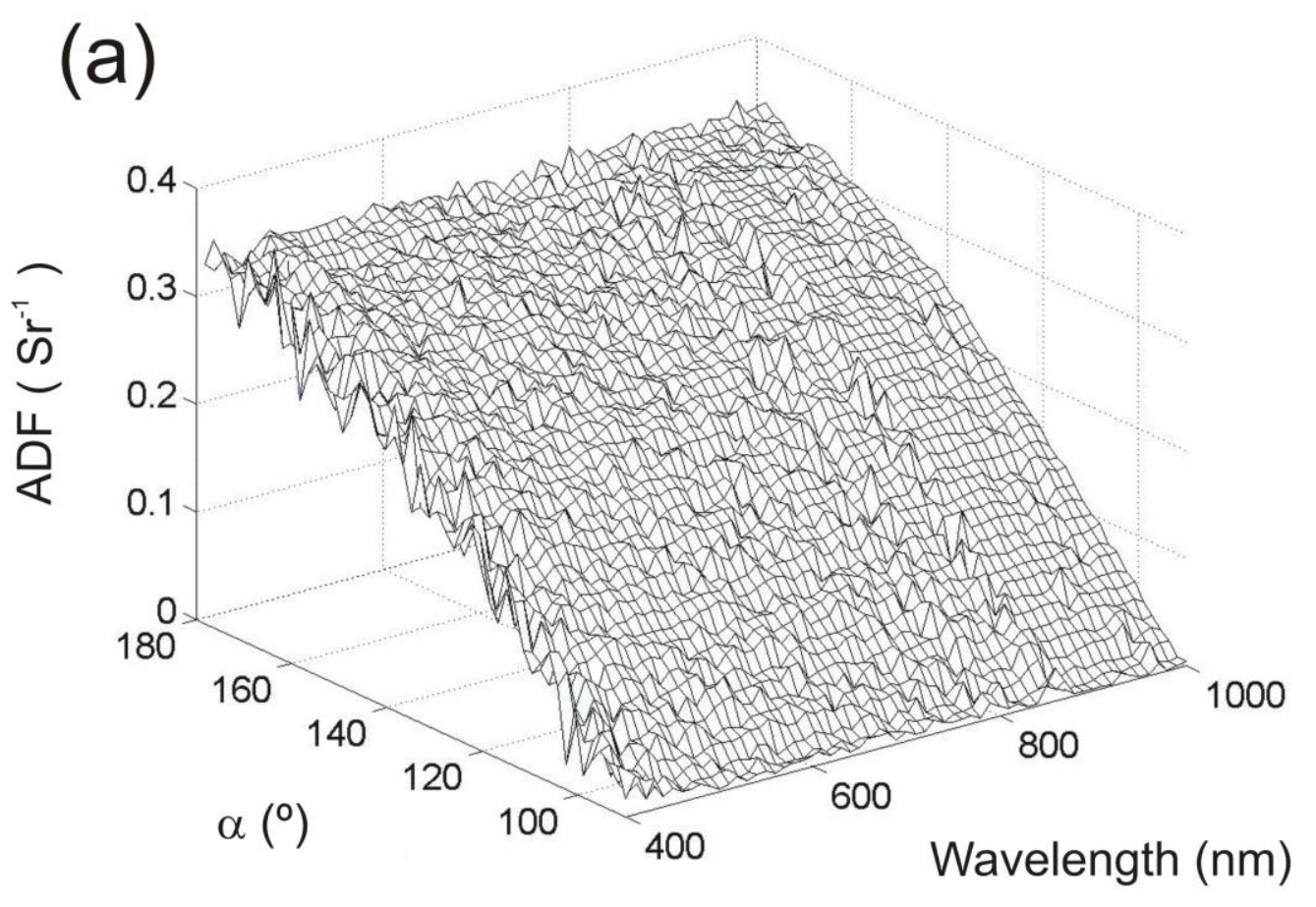

(b)

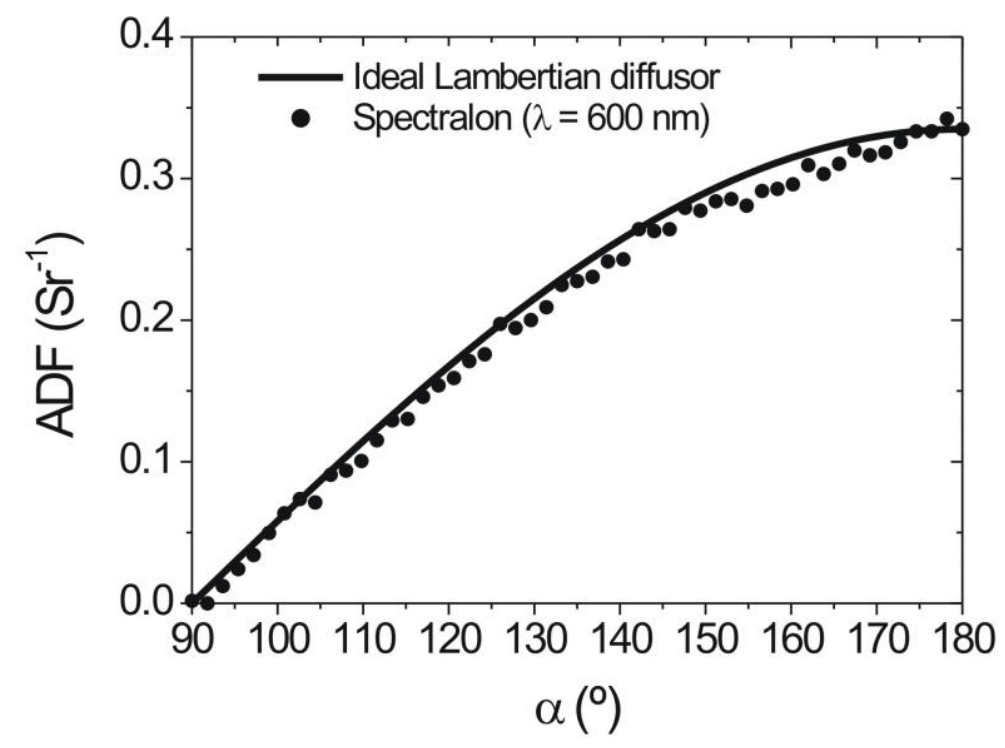



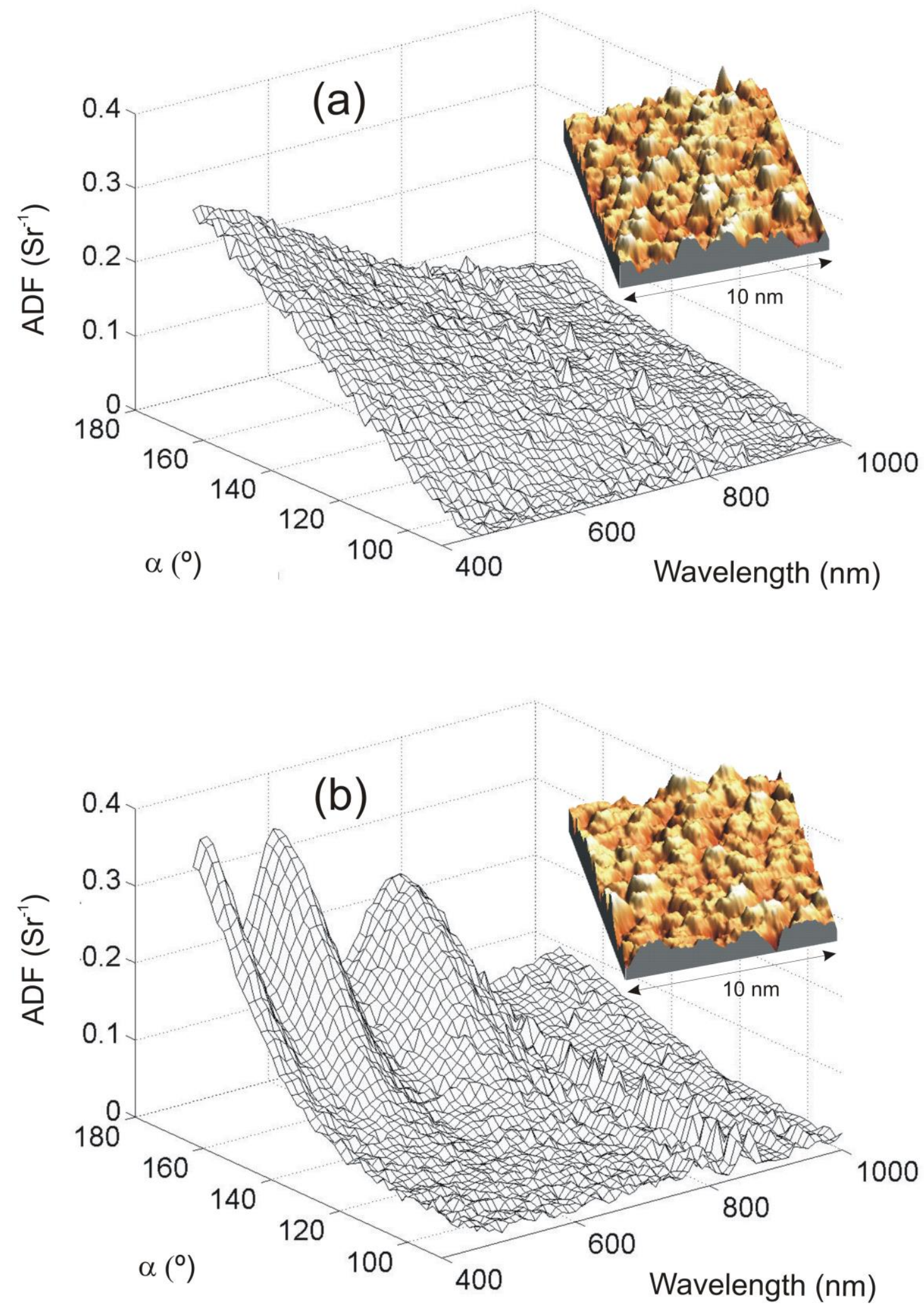


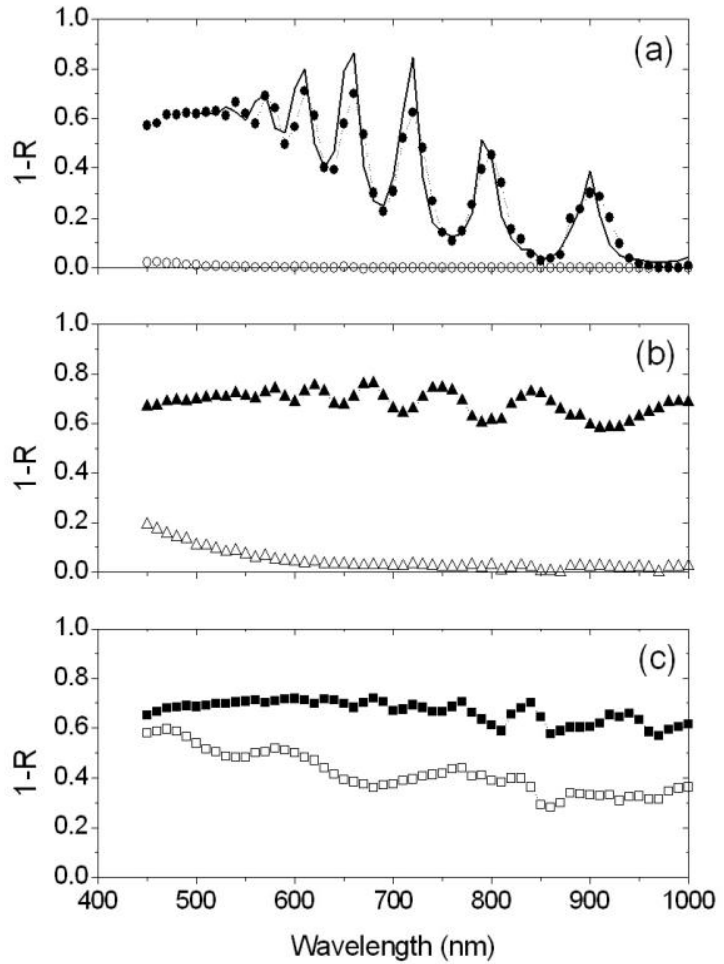